Article

\title{
Are Pharmacy Graduates from an Indonesian University Prepared to Deliver Patient Care?
}

\author{
Desak Ernawati ${ }^{1, *}$, Ya Ping Lee ${ }^{2}$, Bruce Sunderland ${ }^{2}$, Jeff Hughes ${ }^{2}$ \\ 1 Udayana University, Jl. Sudirman Denpasar Bali Indonesia 80222, Indonesia \\ 2 School of Pharmacy Curtin University, Kent Street Bentley WA 6102, Australia \\ * Correspondence: desak.ernawati@postgrad.curtin.edu.au
}

\begin{abstract}
Pharmacists' roles in providing patient care remain limited in Indonesia, hence this study aimed to determine the preparedness of pharmacy graduates from one university in Indonesia to deliver patient care. Pharmacy graduates (both registered pharmacists [104] and recent graduates eligible for registration [45]) were sent a validated self-administered survey. The survey sought their perceptions about whether they had acquired 16 patient care related attributes. Further, it sought their opinion on the desirability of having those attributes. Data were analysed using SPSS version 22.0. Sixteen of $104(15.4 \%)$ registered pharmacists and 40 of $45(88.9 \%)$ recent pharmacy graduates participated in the study. More than $50 \%$ of participants in both groups were female and most participants were aged in their 20s. Of the recent pharmacy graduates the majority perceived they had at least partially acquired four of 16 list attributes. Male and female recent graduates had significantly different beliefs about their leadership ability $(p=0.004)$. In comparison, most registered pharmacists perceived they had 10 out of the 16 listed attributes. The findings of this study suggested that pharmacy graduates should be better prepared to deliver patient care, and that curriculum redesign with expansion of experiential learning is required.
\end{abstract}

Keywords: pharmacy graduates; preparedness; patient care; Indonesia

\section{Introduction}

The concept of pharmaceutical care involves pharmacists delivering patient care has been well accepted in many countries. Hepler and Strand[1] defined pharmaceutical care in 1990 as "The responsible provision of drug therapy for the purpose of achieving definite outcomes that improve a patient's quality of life".This means that pharmacists involved in the management of patients' drug therapy should achieve outcomes resulting in improvement of patients' quality of life. In this model, pharmacists provide patient care in their service. The definition of pharmaceutical care was updated by Cipole [2] in 2007 as "a patient-centred practice in which the practitioner assumes responsibility for a patient's drug related needs and is held accountable for this commitment". However, Blackburn et al. [3] stated that the definitions of Hepler and Strand [1] and Cipole [2] did not provide clear guidelines on how to practice them. For this reason, they suggested the process of care should focusconsistently on patients with the highest priority.

Similar to other developing countries, little is known about the pharmacist's role in patient care in Indonesian practice. Although the Indonesian Government supports the pharmacist role in patient care as seen on PeraturanPemerintah 51 in 2009 about pharmaceutical care, pharmacists in Indonesia in community pharmacy practice are mostly known as businessmen. This may be associated with the fact that pharmacists sell medication as well as household goods in community pharmacy with minimal services aimed at providing patient care. Meanwhile, in the hospital setting, pharmacists dispense medication with minimum direct involvement in clinical activity. This is related to their main roles in the Pharmacy Department which range from ordering the medication from pharmacy distributors to storing and distributing medications to the wards.

Studies in the literature indicate that possible causes of pharmacists' lack of involvement in patient care may include both external and internal pharmacists' factors [4-7]. The external factors may relate to lack of support from health systems and pharmacy organizations. Meanwhile, the 
internal factors may include insufficient numbers of pharmacists to provide patient care. This is because pharmacists are committed and employed to do other roles (for instance, in drug management in hospital setting). Another internal factor is a lack of training which limits pharmacists' competencies to provide patient care. In addition, no pharmacist role models engaged in patient care may cause young pharmacists to have no clear vision of their role as a patient carer. Herman and Susanty [8] found that lack of willingness, knowledge, communication skills and lack of time were factors identified as internal barriers in conducting patient care in an Indonesian community pharmacy setting. Similarly, Nasution et al. [4] found that lack of knowledge and lack of preparedness were internal barriers in an Indonesian hospital setting. They also identified that lack of facilities and lack of support from management were amongst the external barriers to the role of pharmacists within the hospital settings. Pharmacy education plays a significant role in shaping future pharmacists by providing the knowledge, skills and attitudes required for pharmacists. For these reasons, a study was conducted to identify whether pharmacy graduates were prepared to deliver patient care in a university setting in Indonesia.

\section{Materials and Methods}

The pharmacy graduates' attributes and their desirability in delivering patient care was assessed by administering the validated Nova Southeastern University Pharmacy Graduate questionnaire [9]. This questionnaire has also been used and validated in medical graduates [10]. The questionnaire included 16 questions on pharmacists' attributes of a care provider and their desirability to have the attributes. The primary investigator sent a questionnaire via email to 104 registered pharmacists. Their responses were included in the "registered pharmacist group" in the present study. Due to a poor response rate from the registered pharmacist group, 45 pharmacy interns were invited to participate in the study. The primary investigator attended a meeting with the interns two weeks prior to their final examination when the students had finished all their internship courses to become a pharmacist. The primary investigator invited the pharmacy interns to the meeting and administered the graduate questionnaire to the interns. These participants were included inthe "pharmacy interns group" in the present study. The responses of the pharmacy graduates on attributes in delivering patient care and their desirability to have those attributes were analysed descriptively. The responses were compared based on gender. Data were analysed using SPSS ${ }^{\mathrm{TM}}$ version 22.0.

\section{Results}

One hundred and four registered pharmacist graduates from the study university were invited to participate in the study. However, there only 16 registered pharmacists responded. Thus, 45 pharmacy interns were also recruited of whom 40 completed the survey. Nine of $16(56.2 \%)$ registered pharmacists were female and the mean age of the respondents was $24.0 \pm 1.0$ years. The majority of the pharmacy interns $(30 / 40 ; 75.0 \%)$ were also female; with the mean age of the pharmacy interns being $22.4 \pm 3.7$ years. In general, gender did not appear to influence pharmacy interns' perceptions of their acquisition of certain attributes as care providers (Table 1). More than $60 \%$ of female and male pharmacy interns believed that they had acquired the following three attributes required by care providers; namely the ability to listen, had a caring and compassionate nature, and had the motivation to provide patient care. In addition, a further four patient care attributes were reported to be partially acquired by more than $60 \%$ of both female and male pharmacy interns. Those attributes were the adaptability in a changing environment, capacity for independent learning for life, perseverance, and being satisfactory at interpersonal relationships in their professional life. In regards to leadership potential, $50 \%$ of male pharmacy interns stated that they had fully acquired the required leadership potential for patient care compared to only $6.7 \%$ of female pharmacy interns $(\mathrm{p}=0.004)$. The majority of female pharmacy interns $(76.7 \%)$ believed they had only partially acquired leadership potential. 
Despite the fact that the number of registered pharmacist respondents was very small $(n=16)$, data analysis was also conducted. There were more than $60 \%$ of registered pharmacists (males and females) who perceived having the following 10 attributes required to provide patient care (Table 2): ability to recognise their own limitations and strengths; ability to listen; ability to work in a team; ability in having a caring and compassionate nature; excitement with the subject of pharmacy; motivation; open-mindedness; perseverance; satisfaction in interprofessional relationships in professional life, and a spirit of curiosity. Similar to pharmacy interns, male and female registered pharmacists had no significant differences in their perceptions regarding the desirability of proposed attributes required to deliver patient care.

Further comparisons using Fisher's exact test were also conducted on pharmacy interns and registered pharmacist's responses. There were statistically significant differences found regarding the perceived acquisition of the attributes amongst both groups. As can be seen in Table 3 there were a number of attributes where registered pharmacists and pharmacy interns differed in their perceptions of having attained the attribute, namely the ability to inspire confidence in others, adaptability in changing environment, caring and compassionate nature, excitement with the subject of pharmacy, motivation to deliver patient care, open-mindedness, perseverance, and satisfactory in interprofessional relationships in professional life. These differences generally related to registered pharmacists being more confident that they had a particular attribute than their pharmacy intern counterparts. However, there were no significant differences between pharmacy interns and registered pharmacists in regards the desirability of having the attributes to provide patient care.

Table 1. Comparison amongst male $(n=10)$ and female $(n=30)$ pharmacy interns of personal attributes as care providers and desirability to have the attributes using Fisher's Exact Test

\begin{tabular}{|c|c|c|c|c|c|c|}
\hline Personal attributes & Sex & Yes (\%) & Partially (\%) & No (\%) & p-value & Desirability (\%) \\
\hline \multirow{2}{*}{$\begin{array}{l}\text { Ability to recognise own limitations } \\
\text { and strength }\end{array}$} & $\mathrm{F}$ & 56.7 & 43.3 & - & \multirow{2}{*}{0.269} & 100 \\
\hline & M & 80.0 & 20.0 & - & & 100 \\
\hline \multirow{2}{*}{$\begin{array}{c}\text { Ability to inspire confidence in others, } \\
\text { i.e. patients }\end{array}$} & $\mathrm{F}$ & 20.0 & 76.7 & 3.3 & \multirow{2}{*}{0.187} & 73.7 \\
\hline & M & 40.0 & 50.0 & 10.0 & & 100 \\
\hline \multirow{2}{*}{ Ability to listen } & $\mathrm{F}$ & 76.7 & 23.3 & - & \multirow{2}{*}{0.653} & 100 \\
\hline & M & 90.0 & 10.0 & - & & 100 \\
\hline \multirow{2}{*}{ Ability to work in a team } & $\mathrm{F}$ & 73.3 & 26.7 & - & \multirow{2}{*}{0.136} & 100 \\
\hline & M & 50.0 & 40.0 & 10.0 & & 100 \\
\hline \multirow{2}{*}{$\begin{array}{c}\text { Adaptability in a changing } \\
\text { environment }\end{array}$} & $\mathrm{F}$ & 26.7 & 70.0 & 3.3 & \multirow{2}{*}{0.667} & 100 \\
\hline & M & 20.0 & 70.0 & 10.0 & & 100 \\
\hline \multirow{2}{*}{$\begin{array}{l}\text { Capacity for independent learning for } \\
\text { life }\end{array}$} & $\mathrm{F}$ & 16.7 & 73.3 & 10.0 & \multirow{2}{*}{1.000} & 89.3 \\
\hline & M & 20.0 & 70.0 & 10.0 & & 90.0 \\
\hline \multirow{2}{*}{ Capacity for self-audit } & $\mathrm{F}$ & 23.3 & 66.7 & 10.0 & \multirow{2}{*}{0.334} & 88.9 \\
\hline & M & 50.0 & 50.0 & - & & 100 \\
\hline \multirow{2}{*}{ Caring and compassionate nature } & $\mathrm{F}$ & 73.3 & 26.7 & - & \multirow{2}{*}{0.315} & 100 \\
\hline & M & 70.0 & 20.0 & 10.0 & & 100 \\
\hline \multirow{2}{*}{$\begin{array}{l}\text { Excitement with the subject of } \\
\text { pharmacy }\end{array}$} & $\mathrm{F}$ & 70.0 & 30.0 & - & \multirow{2}{*}{0.278} & 100 \\
\hline & M & 50.0 & 50.0 & - & & 100 \\
\hline \multirow{2}{*}{ Leadership potential } & $\mathrm{F}$ & 6.7 & 76.7 & 16.7 & \multirow{2}{*}{$0.004^{*}$} & 100 \\
\hline & M & 50.0 & 30.0 & 10.0 & & 100 \\
\hline \multirow{2}{*}{ Motivation } & $\mathrm{F}$ & 70.0 & 26.7 & 3.3 & \multirow{2}{*}{1.000} & 100 \\
\hline & M & 80.0 & 20.0 & - & & 100 \\
\hline \multirow{2}{*}{ Open-mindedness } & $\mathrm{F}$ & 46.7 & 50.0 & 3.3 & \multirow{2}{*}{0.794} & 100 \\
\hline & M & 40.0 & 60.0 & - & & 100 \\
\hline \multirow[t]{2}{*}{ Perseverance } & $\mathrm{F}$ & 30.0 & 60.0 & 10.0 & \multirow{2}{*}{0.757} & 100 \\
\hline & M & 20.0 & 60.0 & 20.0 & & 100 \\
\hline \multirow{2}{*}{$\begin{array}{l}\text { Satisfactory at interpersonal } \\
\text { relationships in your professional life }\end{array}$} & $\mathrm{F}$ & 23.3 & 70.0 & 6.7 & \multirow{2}{*}{0.859} & 93.3 \\
\hline & M & 30.0 & 60.0 & 10.0 & & 100 \\
\hline \multirow{2}{*}{ Spirit of curiosity } & $\mathrm{F}$ & 40.0 & 60.0 & - & \multirow{2}{*}{0.148} & 100 \\
\hline & M & 70.0 & 30.0 & - & & 100 \\
\hline
\end{tabular}


Tolerance of ambiguity and uncertainty, i.e. decision making with inadequate data
F $\quad 13.3$

46.7

50.0
40.0

30.0

0.888

50.0

80.0

Table 2. Comparison amongst male $(n=7)$ and female registered pharmacists $(n=9)$ of personal attributes as care providers and desirability to have the attributes

\begin{tabular}{|c|c|c|c|c|c|c|}
\hline Personal Attributes & Sex & Yes (\%) & Partially (\%) & No $(\%)$ & p-value & Desirability (\%) \\
\hline \multirow{2}{*}{$\begin{array}{l}\text { Ability to recognise own limitations } \\
\text { and strength }\end{array}$} & $\mathrm{F}$ & 77.8 & 22.2 & - & \multirow{2}{*}{1.000} & 100 \\
\hline & M & 85.7 & 14.3 & & & 85.7 \\
\hline \multirow{2}{*}{$\begin{array}{c}\text { Ability to inspire confidence in others, } \\
\text { i.e. patients }\end{array}$} & $\mathrm{F}$ & 55.6 & 44.4 & & \multirow{2}{*}{0.413} & 100 \\
\hline & M & 71.4 & 14.3 & 14.3 & & 100 \\
\hline \multirow{2}{*}{ Ability to listen } & $\mathrm{F}$ & 100 & - & - & \multirow{2}{*}{0.143} & 100 \\
\hline & M & 71.4 & 28.6 & - & & 88.9 \\
\hline \multirow{2}{*}{ Ability to work in a team } & $\mathrm{F}$ & 100 & - & - & \multirow{2}{*}{0.400} & 100 \\
\hline & M & 71.4 & 28.6 & - & & 88.9 \\
\hline \multirow{2}{*}{$\begin{array}{l}\text { Adaptability in a changing } \\
\text { environment }\end{array}$} & $\mathrm{F}$ & 77.8 & 22.2 & - & \multirow{2}{*}{0.329} & 100 \\
\hline & M & 42.9 & 57.1 & - & & 100 \\
\hline \multirow{2}{*}{$\begin{array}{c}\text { Capacity for independent learning for } \\
\text { life }\end{array}$} & $\mathrm{F}$ & 55.6 & 44.4 & - & \multirow{2}{*}{0.608} & 100 \\
\hline & M & 28.6 & 57.1 & 14.3 & & 100 \\
\hline \multirow{2}{*}{ Capacity for self-audit } & $\mathrm{F}$ & 44.4 & 44.4 & 11.2 & \multirow{2}{*}{0.776} & 100 \\
\hline & M & 28.6 & 71.4 & - & & 100 \\
\hline \multirow{2}{*}{ Caring and compassionate nature } & $\mathrm{F}$ & 100 & - & - & \multirow[b]{2}{*}{ - } & 100 \\
\hline & M & 100 & - & - & & 100 \\
\hline \multirow{2}{*}{$\begin{array}{l}\text { Excitement with the subject of } \\
\text { pharmacy }\end{array}$} & $\mathrm{F}$ & 100 & - & - & \multirow{2}{*}{-} & 100 \\
\hline & M & 100 & - & - & & 100 \\
\hline \multirow{2}{*}{ Leadership potential } & $\mathrm{F}$ & 50 & 50 & - & & 100 \\
\hline & M & 42.9 & 42.9 & 14.3 & & 100 \\
\hline \multirow{2}{*}{ Motivation } & $\mathrm{F}$ & 100 & - & - & \multirow[b]{2}{*}{ - } & 100 \\
\hline & M & 100 & - & - & & 100 \\
\hline \multirow{2}{*}{ Open-mindedness } & $\mathrm{F}$ & 77.8 & 22.2 & - & \multirow{2}{*}{0.486} & 100 \\
\hline & M & 85.7 & 14.3 & - & & 100 \\
\hline \multirow{2}{*}{ Perseverance } & $\mathrm{F}$ & 88.9 & 11.1 & - & \multirow{2}{*}{1.000} & 100 \\
\hline & M & 71.4 & 28.6 & - & & 100 \\
\hline Satisfactory at interpersonal & $\mathrm{F}$ & 66.7 & 33.3 & - & \multirow{2}{*}{0.604} & 100 \\
\hline relationships in your professional life & M & 71.4 & 28.6 & - & & 100 \\
\hline \multirow{2}{*}{ Spirit of curiosity } & $\mathrm{F}$ & 77.8 & 22.2 & - & \multirow{2}{*}{1.000} & 100 \\
\hline & M & 71.4 & 28.6 & - & & 83.3 \\
\hline Tolerance of ambiguity and & $\mathrm{F}$ & 11.1 & 77.8 & 11.1 & & 88.9 \\
\hline $\begin{array}{l}\text { uncertainty, i.e. decision making with } \\
\text { inadequate data }\end{array}$ & M & 42.9 & 28.6 & 28.6 & 0.211 & 80.0 \\
\hline
\end{tabular}

Table 3. P-values of perception of having personal attributes and desirability amongst pharmacy interns $(n=40)$ and registered pharmacists $(n=16$

\begin{tabular}{cccc}
\hline \multirow{2}{*}{ Personal Attributes } & Pharmacy & p-value \\
\cline { 3 - 4 } Ability to recognise own limitations and strength & Graduates & Perception & Desirability \\
\hline Ability to inspire confidence in others, i.e. patients & Registered & 0.218 & 0.286 \\
Ability to listen & Recent & $\mathbf{0 . 0 1 8 ^ { * }}$ \\
Ability to work in a team & Registeredt & 0.525 \\
\end{tabular}


Adaptability in a changing environment

Capacity for independent learning for life

Capacity for self-audit

Caring and compassionate nature

Excitement with the subject of pharmacy

Leadership potential

Motivation

Open-mindedness

Perseverance

Satisfactory at interpersonal relationships in your professional life

Spirit of curiosity

Tolerance of ambiguity and uncertainty, i.e. decision making with inadequate data

\section{Registered}

Recent

Registeredt

Recent

Registered

Recent

Registered

Recent

Registered +

Recent

Registered +

Recent

Registered

Recent

Registered

Recent

Registered

Recent

Registered

Recent

Registered

Recent

Registered

Recent

Registered
0.568

0.892

0.079

$0.021^{*}$

$0.005^{*}$

$0.032 *$

0.033*

0.001*

$0.008^{*}$

0.273

0.358

0.1

Notes: + indicated the group had higher proportion of perceived believe of having the attribute; ${ }^{*}$ showed significant difference

\section{Discussion}

Pharmacy graduates (both registered pharmacists and pharmacy interns) from the study university either fully or partially perceived that they had the attributes necessary to be care providers. In addition, the pharmacy graduates desired to have those attributes as pharmacists in delivering patient care. These results suggest that the pharmacy curriculum in the study university had fostered some of attributes necessary for pharmacists delivering patient care. However, registered pharmacists, one to two years after graduation, perceived that they had acquired more of the attributes that their intern counterparts. This difference islikely related to registered pharmacists acquisition of further attributes through real-life experiences in their place of work. This may also stem from the greater sense of responsibility that comes with being a registered pharmacist. This may explain the higher proportion of registered pharmacists who perceived having such attributes as the ability to inspire confidence in others and satisfactory interpersonal relationships in their professional life compared to pharmacy interns. However, it should be noted that the proportion of registered pharmacists who participated in the current study was very small compared to pharmacy interns, thus these findings should be viewed with some caution.

The results of this study identified that although the majority of pharmacy graduates desired to be long life learners, most pharmacy interns reported only partial attainment of this attribute. Pharmacy graduates should be long life learners because it is essential to ensure their ongoing 
competency to practice as pharmacists [11]. In addition, although pharmacy interns believed that they have the ability to work in a team, they were not totally satisfied with their interprofessional relationships in their professional life. This might reflect the fact that there is limited experiential learning during their undergraduate course. Although the number of registered pharmacists in the current study was low $(n=16)$, registered pharmacists were more confident in their interprofessional relationships in their professional life than pharmacy interns. This is likely to reflect the influence of professional practice in development of professional identity and the confidence to interact with other healthcare professionals [12]. This suggests that the pharmacy curriculum needs to be amended to provide more pharmacy practice experience during the undergraduate course. This may improve pharmacy graduates' confidence in having the attributes to provide patient care.

Findings from this study indicated that the pharmacy curriculum at the study university needs to be redesigned to allow pharmacy graduates to fulfil a number of their roles as a seven-star pharmacist. The concept of the seven-star pharmacist was introduced by the WHO in 2000 [13]. Seven-star pharmacists must possess specific knowledge, attitudes, skills, and behaviours in support of their roles" [11]. These roles include care-giver, decision-maker, communicator, manager, long-life learner, teacher and leader. A report from the WHO experts group on preparing future pharmacists for their roles in the healthcare system highlighted that curriculum change and partnership amongst leaders in the university and pharmacy profession are essential to allow pharmacist to fulfil those roles [11]. Acknowledging the fact that pharmacy graduates in the study university indicated a lack of preparedness in delivering patient care, it is recommended that the current pharmacy curriculum be amended. Amendments should involve both the course content as well as practical experience. The curriculum redesign should focus on ensuring pharmacy graduates feel more prepared to deliver patient care. The curriculum should be adjusted by introducing more experiential learning; which commences early and continues throughout the course. Experiential learning allows pharmacy students to reflect on real practice experience, to conceptualise the theory, and to actively participate in practice [thus gain real-life experience] [14,15].

\section{Conclusions}

This study found that pharmacy graduates of the study university perceived that the lacked preparedness as care providers. As pharmacy practice moves away from medicine supply to patient care then pharmacy curriculum redesign focused on both content and experiential learning will be essential to prepare pharmacy graduates to be care providers

Acknowledgments: This manuscript is an extract (with modifications) from the doctoral thesis of the corresponding author.The study was funded by the DFAT Australia as part of Doctoral scholarship of the corresponding author.

Ethics Approval and Consent to Participate: Ethical approval was obtained from the study university No. 64/UN.14.2/Litbang/II/2012 and from Curtin University HR175/2011.

Author Contributions: JH, BS, YPL concieved and designed the study, DKE performed, analysed and wrote the report.

Conflicts of Interest: The authors declare no conflict of interest.

\section{References}

1. Hepler, C.D.; Strand, L.M. Opportunities and responsibility in pharmaceutical care. Am J Hosp Pharm 1990, $47,533-43$.

2. Cipole, R.J. Pharmaceutical care practice: the clinician's guide $2^{\text {nd }}$ ed; McGraw-Hill Companies: New York, USA, 2007.

3. Blackburn, D.F.; Yakiwchuck, E.M.; Jorgenson, Dj.; Mansell, K.D. Proposing a redefinition of pharmaceutical care. Ann Pharmacother 2012, 46, 447-9. 
4. Nasution, A.; Sulaiman, S.S.; Shafie, A. Pharmacists' perception of their role and assessment of clinical pharmacy education to improve clinical pharmacy services in Indonesian hospitals. Int J Pharm Pharm Sci 2014, 6(11), 177-80.

5. Azhar, S.; Hassali, M.A.; Izham, M.; Ibrahim, M.; Ahmad, M.; Masood, I. The role of pharmacists in developing countries: the current scenario in Pakistan. Hum Resour Health2009,7(54).

6. Jorgenson, D.; Dalton, D.; Farrell, B.; Tsuyuki, R.; Dolovich, L. Guidelines for pharmacists integrating into primary care team. Can Pharm J 2013, 146, 343-52

7. Rubio-Valera, M.; Chen, T.F.; O'Reilly, C.L. New roles for pharmacists in community mental health care: a narative review. Int J Environ Res Public Health 2014, 11, 10967-90.

8. Herman, M.J.; Susyanty, A.L.; An analysis of pharmacy services by pharmacist in community pharmacy. BuletinPenelitianSistemKesehatan 2012,15, 271-81

9. Droege, M.;Assa-Eley, M.T. Pharmacists as care providers: personal attributes of recent pharmacy graduates. Am J Pharm Educ 2005, 69, 290-5.

10. Clack, G.; Head, J. Gender differences in medical graduates' assessment of their personal attributes. Med Educ 1999, 33(2), 101-5.

11. World Health Organization,The role of the pharmacist in the health care system.Vancouver, Canada:, 1997 27-29 August 1997. Report No.

12. Richardson B. Professional development: 2. Professional knowledge and situated learning in the workplace. Physiotherapy 1999, 85(9), 467-74.

13. Wiedenmayer, K.; Summers, R.S.; Mackie, C.A.; Gous, A.G.S.; Everard, M.; Tromp, D. Developing pharmacy practice: a focus on patient care, The Netherlands: World Health Organisation and International Pharmaceutical Federation; 2006.

14. Kolb, D.A. The process of experiential learning. Experiential learning: experience as the source of learning and development. Prentice Hall: New Jersey, USA,1984, pp. 20-38.

15. Hughes, J.; Parsons, R.; Sargant, S. Influence of the pharmacy curriculum on students' preparedness for patient care. Res Social Adm Pharm 2012,8, e12-e3.

(C) 2016 by the authors; licensee Preprints, Basel, Switzerland. This article is an open access article distributed under the terms and conditions of the Creative Commons by Attribution (CC-BY) license (http://creativecommons.org/licenses/by/4.0/). 